$\begin{aligned} \text { LA-UR } & 97-2722 \\ & \text { CONF-9706/13-- }\end{aligned}$

TITLE: CABALLERO: A HIGH CURRENT FLUX COMPRESSOR SYSTEM FOR 100 MJ LINER SOLID LINER EXPERIMENTS

RECEIVED

NOV 031997

AUTHOR(S):

R. E. REINOVSKY, DX-DO

I. R. LINDEMUTH, XPA

OSTI

E. A. LOPEZ, DX -3

J. H. GOFORTH, DX-3

S. P. MARSH, DX -3

SUBMITTED TO: $11 \mathrm{TH}$ IEEE INTERNATIONAL PULSED POWER CONFERENCE

JUNE 29-JULY 2, 1997; BALTIMORE, MD

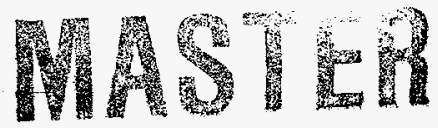

DISTRISUMON OF THIS DOCUMENT IS UNLITIED

By acceptance of this article. the publisher recognizes that the U.S. Government retains a nonexclusive. royalty-free license to publish or reproduce the oudished form of this contribution. Or to allow others to do so. for U.S. Government Durposes.

The Los Alamos National Laboratory requests that the pubitisher identity this article as work Dertormed under the auspices of the U.S. Department of Energy
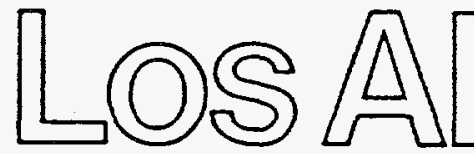


\section{DISCLAIMER}

This report was prepared as an account of work sponsored by an agency of the United States Government. Neither the United States Government nor any agency thereof, nor any of their employees, makes any warranty, express or implied, or assumes any legal liability or responsibility for the accuracy, completeness, or usefulness of any information, apparatus, product, or process disclosed, or represents that its use would not infringe privately owned rights. Reference herein to any specific commercial product, process, or service by trade name, trademark, manufacturer, or otherwise does not necessarily constitute or imply its endorsement, recommendation, or favoring by the United States Government or any agency thereof. The views and opinions of authors expressed herein do not necessarily state or reflect those of the United States Government or any agency thereof. 


\section{DISCLAMMER}

Portions of this document may be illegible in electronic image products. Images are produced from the best arailable original document. 


\title{
Caballero: A High Current Flux Compressor System For 100 MJ Solid Liner Experiments
}

\author{
R. E. Reinovsky, I.R. Lindemuth, E. A. Lopez J.H. Goforth, S. P. Marsh \\ Los Alamos National Laboratory, New Mexico, USA
}

\begin{abstract}
Pulse power systems delivering in excess of $100 \mathrm{MJ}$ represent one of the next major challenges to the pulse power community. While a laboratory pulse power system in this energy range is feasible, it represents a very substantial investment of both time and resources. Prudence requires that fundamental proof-of-principle for the contemplated application is established before such massive resources are committed. Explosive pulse power systems using magnetic flux compression provide a direct path to such demonstrations. Furthermore, as energy requirements grow, single use explosive systems may represent the only affordable source of ultra-high energy environments.

Currently two flux compressor configurations are under consideration for powering solid liner implosions at currents above $100 \mathrm{MA}$ and at energies above $100 \mathrm{MJ}$. A simultaneously initiated coaxial flux compressor (Ranchero) is described in a companion paper. A modular, center initiated disk configuration, generally patterned after the DEMG ${ }^{1}$ is the other candidate. Either can drive loads directly or can conceptually be connected in parallel with flat plate transmission lines to increase current delivery.

Phenomenological models and conceptual designs for DEMG systems have been previously reported. In this paper we report the results of the experimental test of a first generation disk generator system. Individual disk segments have been tested with framing camera diagnostics to evaluate overall performance, dynamics and fabrication failure points. In general no bulk failures were observed in several shots and the critical weld joints maintained their integrity for at least $4 \mu \mathrm{s}$ after arrival of the detonation front. Single module pulse power experiments have been conducted at reduced initial current $(1.5-2.0 \mathrm{MA})$ with a fixed inductance load of $0.22 \mathrm{nH}$.
\end{abstract}

\section{Introduction}

Massive, cylindrical liners imploded by the magnetic pressure produced by large (axial) currents can produce a variety of high energy density environments in experimental assemblies located in a central target. When imploded in free flight to velocities of a few tens of $\mathrm{km} / \mathrm{sec}$ and kinetic energies of tens of megajoules per centimeter of height, liners are attractive impactors for driving strong shocks in the target. When filled with a suitably compressible material, for example a magnetized fusion plasma, liners can deliver almost adiabatic compression to the target converting its kinetic energy into internal energy and dramatically heating the target. And when the liner is placed surrounding a (small) nearly incompressible target material, for example a condensed noble gas, a liner can deliver enormous pressure to the target almost isentropically

Of the several ways that liners can be applied, delivery of strong shocks (up to 100 Mbar) is perhaps the most technically challenging. Target dimensions of a centimeter in radius and a few centimeters in height are attractive for many experiments. With proper choice of initial geometry, liner material, driving current and time-scale, the liner can be designed to arrive at the $(1 \mathrm{~cm})$ target radius with the required velocity,

\footnotetext{
- This work supported by the US Department of Energy
} 
with a significant amount of the liner unmelted, and with the majority of the liner at or above normal density?

\section{Design of CABALLERO-40 Test System}

To initially explore the performance of the Disk Explosive Magnetic Generator (DEMG), a system (Caballero-40) was designed with a module diameter of $40 \mathrm{~cm}$. While optimizing the generator design for driving large imploding liners leads to a somewhat larger disk diameter (about $60 \mathrm{~cm}$ ), the size of the Caballero -40 test system was selected specifically allow comparison with published data from systems of similar scale ${ }^{1}$. As a side benefit the test system was both convenient and economical to build and operate. Design objectives for the characterization system included output current of 50-100 MA using an initial current of 6-8 MA, operating time of 20-25 $\mu \mathrm{s}$ and maximum dl/dt of $10^{13} \mathrm{~A} / \mathrm{s}$,

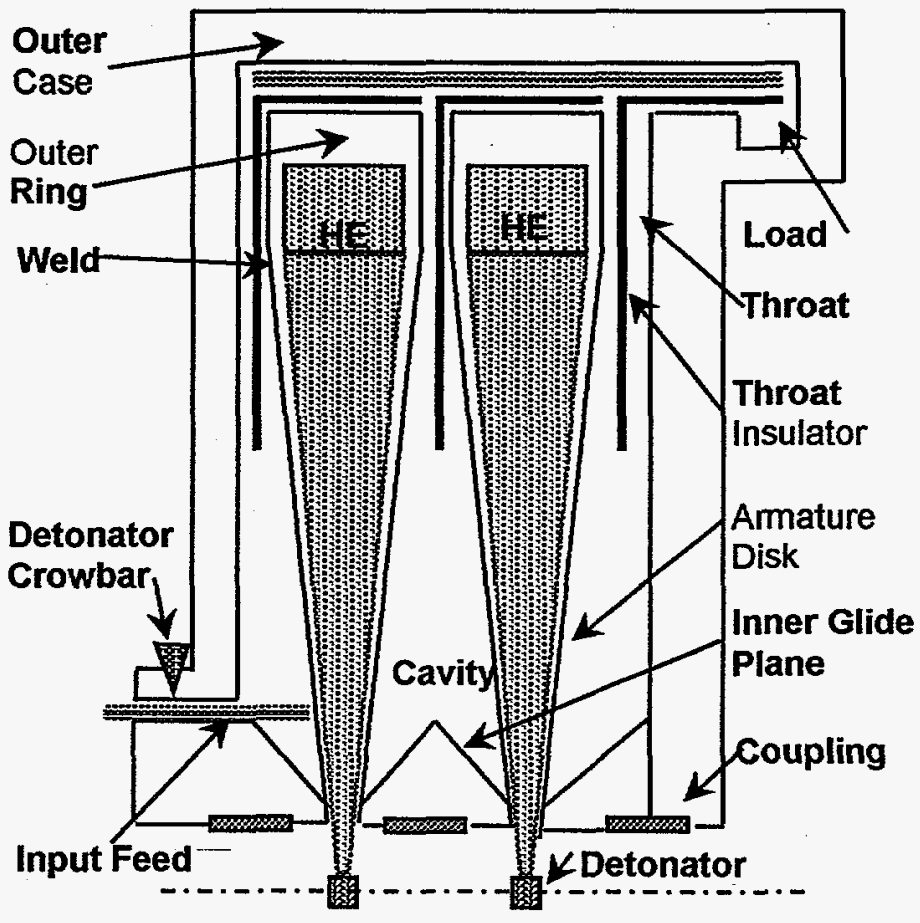

Figure 1. Conceptual Design of DEMG

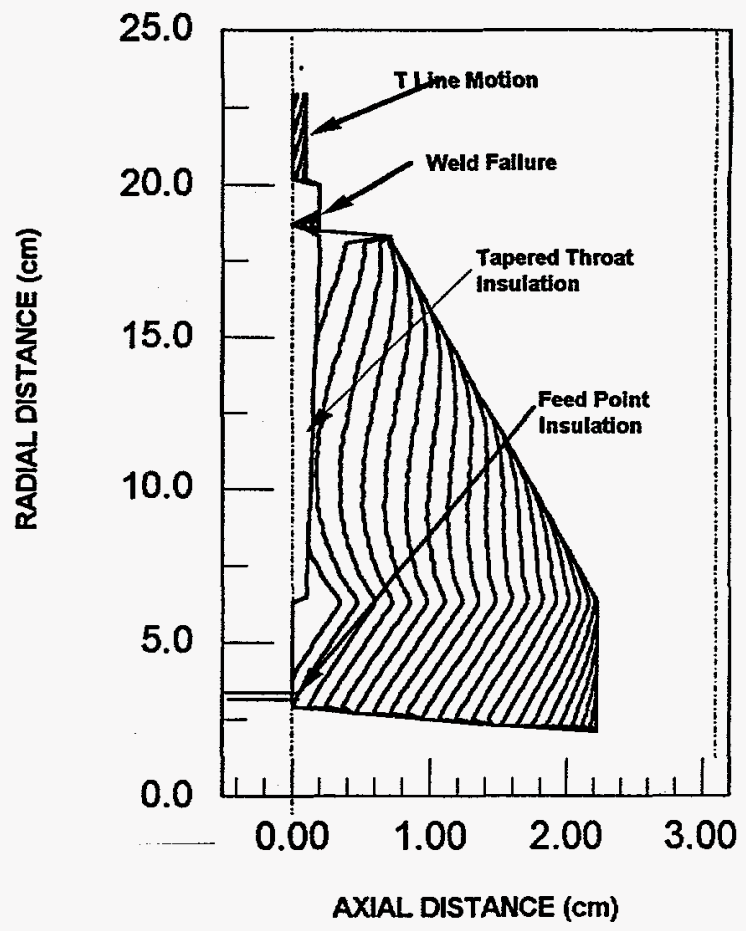

Figure 2 Dynamic Compression of DEMG cavity

Conceptual design of the test system is shown in Fig 1. The inductance of the system is made up of several components. $L_{\mathbb{N}}$ is the time invariant inductance of the current feed through which initial flux is loaded into the generator and includes additional inductance associated with the crowbar switch which isolates the generator from the initial current source. $L_{M}$ is the inductance associated with each module and scales with the number of modules. $L_{M}$ can be further subdivided into a cavity inductance $L_{C}(t)$ which, ideally, approaches zero at the end of the generator run and does not contribute to the inductance in which the system stores energy and $\mathrm{L}_{T}$, a time invariant inductance which represents the inductance of the throat leading from each cavity to the coaxial transmission line plus the inductance of the outer coaxial transmission line that is attributable to each cavity. $L_{\pi}$ is the inductance of a transmission line segment between the generator and load $L_{L}$. The inductances $L_{1 N} L_{T} L_{T}$ and any initially non-zero part of $L_{L}$ are time invariant and contribute to the final storage inductance $\left(L_{S}\right)$. In practice, each of the components, $L_{\mathbb{N}} L_{T}, L_{T L}$, can have time varying components, especially at late time. These variations are, however, ignored for first analysis but can be taken into account in more detailed modeling.

For the Caballero-40 system, the initial inductance of a generator cavity, $L_{c}$, was $15.64 \mathrm{nH} /$ module and the load inductance was $0.22 \mathrm{nH} /$ module. The copper envelope of the disk armature was constructed from two disks made from 1/8". copper sheet stock welded to a machined outer ring at the $18.17 \mathrm{~cm}$ 
radius. The copper disks were pressed to the required profile before being welded to the ring. . The inner "glide plane" was machined from copper stock and welded to the armature disk armature. Approximately $8.1 \mathrm{~kg}$ of a castable HMX based high explosive formulated with an inert binder that cures by chemical reaction was injected into the armature through a hole in the outer ring. To maintain the precise shape of the armature disks, the metal envelope was supported in a profiled fixture during the injection molding process. The hole in the outer ring was subsequently filled with a copper plug, cooled before inserting, to make a moderate interference fit. The detonation velocity of the explosive is $8.311 \mathrm{~mm} / \mathrm{ms}$ and the dimensionless energy used in the Gurney model was 2.40 .

Individual modules are designed to be assembled to subsequent stages with a threaded steel coupling. The coupling provided additional mechanical strength for the inner "glide plane" which must support the substantial magnetic pressure $(25 \mathrm{kB})$ produced by the 10-15 MA currents present while the armature is in contact with the glide plane.

The gap between the disk stages, the "throat", through which the generator delivers flux to the coaxial transmission line, is insulated with a $2 \mathrm{~mm}$ thick insulator machined of high density polyethylene. In addition to the machined inter-stage insulators, the coaxial transmission line is insulated with a multi-layer

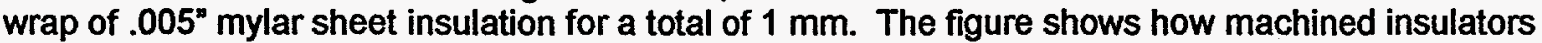
accommodate multiple stages and how the mylar wrap insulates the gaps between the machined insulators. For the test system, the total inductance of the output gap and coaxial transmission line is about $0.14 \mathrm{nH} / \mathrm{stage}$. For a load inductance of $0.22 \mathrm{nH} / \mathrm{stage}$ and a peak dl/dt of $10^{13} \mathrm{Ass}$, the peak voltage across the output gap would be about $4 \mathrm{KV}$. For multi-disk systems the peak voltage at the load is $\mathrm{N}$ times the voltage per inter-stage gap, reduced by the inductive drop in the coaxial transmission line and could reach $25-50 \mathrm{KV}$ for a 10 stage system. To support this voltage in systems with many stages, it may be desirable to increase the thickness of the mylar wrap for stages near the load. This will be reflected in a modest increase in $L_{T}$

The input inductance, $L_{\mathbb{N}}$ consisted of a section of coaxial line with $1.27 \mathrm{~mm}$ of insulation crowbared by 4 detonator switches about $7 \mathrm{~cm}$ from the generator. The geometric inductance of this section was $0.57 \mathrm{nH}$, but as shown in the figure, this inductance is removed from the circuit by the action of the armature midway through the compression process. This inductance contributes to the flux in the system at early time, and as will be seen later, its removal at the correct time is necessary to explain the operation of the system in detail.

\section{Phenomenological Operation of CABALLEP.O-40}

A phenomenological model of disk flux compressor operation has been described ${ }^{3}$ The model uses a series of one-dimensional calculations of the axial motion of the generator wall to approximately describe the two-dimensional compression of flux in the DEMG cavity. Motion of the wall driven by high explosive is calculated by a Gurney model, which uses momentum and energy balance to calculate the initial wall velocity. In this model, a detonation velocity and a dimensionless detonation energy density describe the performance of the explosive. Wall motion is opposed by magnetic pressure produced by the time dependent currents flowing in the walls of the generator cavity. Flux loss axially into the wall is calculated by a magnetic diffusion treatment in the finite conductivity of the copper wall. The current flowing in the wall heats the wall non-uniformly in the axial direction, and the diffusion calculation tracks flux penetration into a wall of varying conductivity, permitting an approximate evaluation of the non-linear flux loss in the cavity walls. Cavity motion and wall losses are expressed as time dependent generator inductance and resistance, and a self-consistent circuit calculation couples generator behavior with that of a imploding liner load.

Operation of the Caballero-40 generator as calculated by the phenomenological model is shown in Figure 2. The figure shows the profile of the inner surface of the thin current carrying copper wall as it compresses a symmetric half section of the generator cavity. The explosive is detonated in a single point on the axis and the detonation front moves radially outward. Driven axially by the explosive, the cavity wall begins to compress first near the axis, pushing flux outward through the throat of the cavity and into the coaxial transmission line. When the cavity wall arrives at the symmetry plane, it contacts either an end 
wall, or a symmetrically moving cavity wall from an adjacent disk. If the moving wall encounters no insulation as it arrives on the mid-plane, it makes (perfect) contact. If it encounters insulation, the moving wall is immediately brought to zero velocity without compressing the "ideal" insulation. Since it does not make contact, a cavity containing flux results. The model tracks such cavities and determines if flux in the cavity can ultimately be available to the load or if it is "cut-off". Time interval between contours in Figure 2 is $1 \mu \mathrm{s}$.

As shown in Figure 1, a short cylindrical section of insulation from the input feed protrudes into the cavity at a radius of about $2.9 \mathrm{~cm}$. As the cavity wall moves up the glide plan approaching the feed slot, it compresses the feed insulation. The model makes no attempt to calculate the precise shape of the cavity formed by the crushed and compressed feed insulation, but since the volume occupied by this insulation is near the axis, it can contains significant magnetic flux and represent significant inductance. For the Caballero- 40 system, this "flux pocket" is modeled by introducing a rectangular volume of insulation ( 2 $\mathrm{mm}$ by $0.1 \mathrm{~mm}$ ) as shown in Figure 2.

Similarly, as the cavity wall contact point moves up the symmetry plane, it encounters the disk shaped insulation protruding into the cavity from the generator throat. The insulation stops the motion of the cavity wall thus limiting the ultimate compression achievable. As will be seen in the experimental data the effect of the volume and location of insulation in the cavity can measurable affect generator performance.

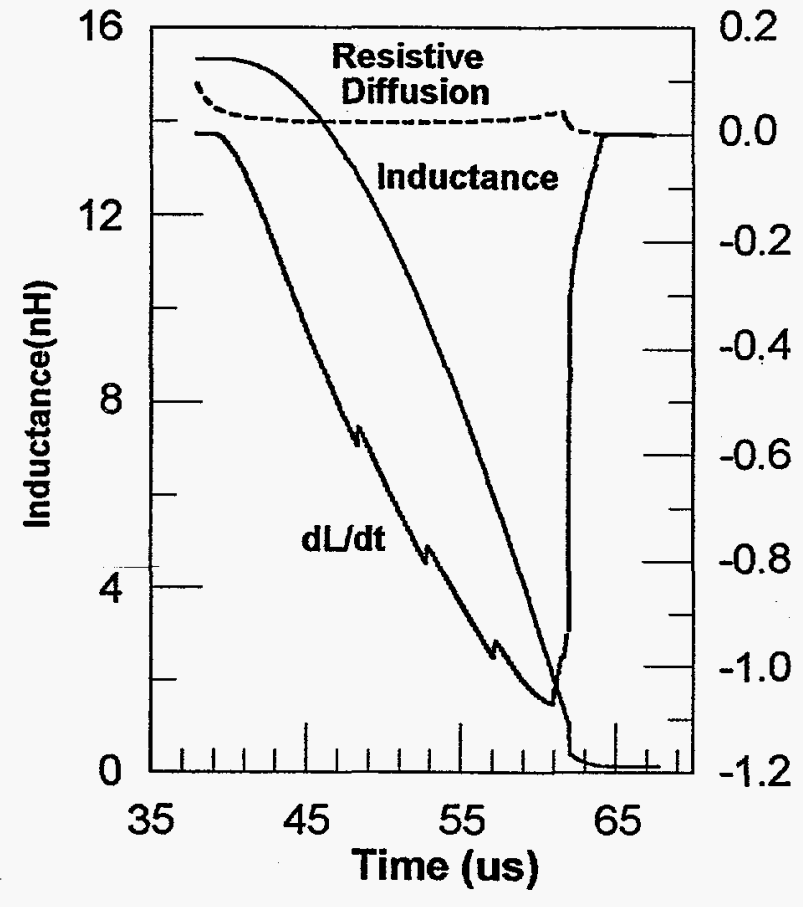

Figure 3. Inductance and $L$-dot and resistive losses for the Cab-40 configuration

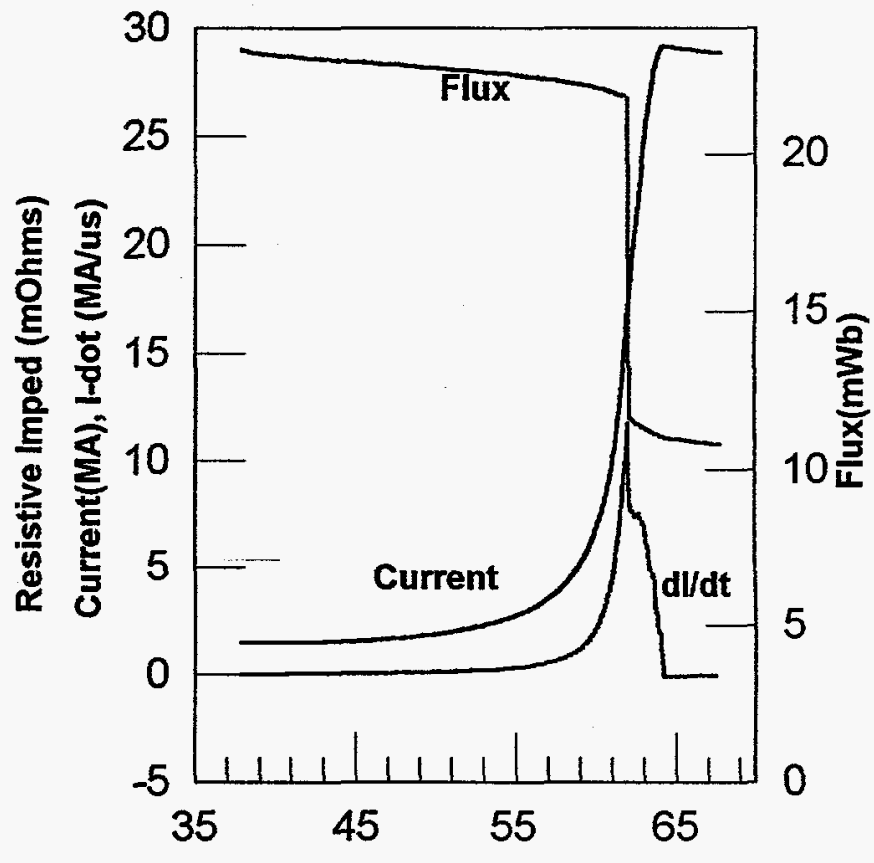

Time (us)

Figure 4 Current dl/dt and Flux for CAB-40 with initial current of $1.5 \mathrm{MA}$

In a circuit, the dynamic cavity compression illustrated in Figure 2 can be described as a time dependent inductance, time derivative of the inductance and the equivalent resistance due to flux diffusion losses. These parameters, for a cavity configuration like Figure 2 but with all insulation removed, are plotted as functions of time in Figure 3. Both dL/dt and flux diffusion losses are resistive impedances, but dL/dt is a negative impedance corresponding to a source term (the conversion of mechanical energy to electrical energy in the compression process. Resistive losses are seen to be high in the beginning of the calculation because the intial conditions on the flux place all the magnetic field in the cavity with none in the wall so diffusion is exaggerated at early times. Resistive losses increase near the end as the 
conductors heat and decrease in conductivity. Figure 4 shows the current, current derivative and flux in a circuit containing one disk section and a $0.22 \mathrm{nH}$ load with initial current of $1.5 \mathrm{MA}$. The substantial decrease in the flux in the system, occurring at $62.0 \mu \mathrm{s}$, (losing about $40 \%$ of the flux) is the result of the formation of a $0.54 \mathrm{nH}$ cavity on the axis.

\section{System Performance}

Performance of the Caballero 40 system has been assessed in both dynamic motion experiments, characterizing the behavior of a disk element, and in electrical experiments where the disk element is contain in a stator.

For the dynamic motion experiments high speed framing camera photographs of the motion of the thin armature walls in one isolated disk element were made. Of particular concern in the CABALLERO-40 design was the mechanical strength and integrity of the weld that joined the thin armature disks to the thick outer ring at $18.17 \mathrm{~cm}$. High speed photographs taken at $2 \mu \mathrm{s}$ intervals, show significant eruption of high explosive gas through this weld joint at about $28.5 \mu \mathrm{s}$ from the time of detonation on axis. This is almost $6 \mu \mathrm{s}$ after arrival of the detonation front at the radius of the weld. High explosive products erupting at this point would be expected to rapidly penetrate the insulation in the gap at the throat of the cavities causing shorting of the gap and ending the delivery of flux to the load.

In the electrical experiments a small array of contact probes (4-5 probes on 4 radial lines) were located in the end wall to qualitatively assess azimuthal symmetry and radial speed of the contact point with the end walls. The timing observed by the probes was consistent with that calculated in the model. Electrical performance of the Cab- 40 system was evaluated in tests of a single disk module operating into a 0.22 $\mathrm{nH}$ load. These tests were conducted with limited initial current (1.5 MA) to evaluate fundamentals of generator operation. Current measurements were made at the input to the generator and in the load using an optical current diagnostic based on Faraday rotation in a quartz fiber. The results of the first electrical test are shown in Figure 5 along with model predictions for several insulation configurations. On the experimental time scale, the explosive is detonated on axis at $36.3 \mu \mathrm{s}$. All models correspond closely to the measured performance until $57 \mu$ s. At this time the model shows that the armature begins to impact on the insulation at the feed point and this dominates the subsequent behavior. The current in the model case with no insulation continues to climb steeply reaching 30 MA (Fig 4). At $61.3 \mu$ s the moving walls contact the polyethylene throat insulation which extends into the cavity to a radius of $6.3 \mathrm{~cm}$ as shown in Figure 2. In the model, the armature stops upon impact with the insulator resulting in less than complete compression of flux in the cavity and the predicted current for the case considering only throat insulation is about $20 \mathrm{MA}$. With both throat and feed point insulation considered, the peak current is about $17 \mathrm{MA}$ and the model compares quite well with the experiment until $62 \mu \mathrm{s}$. Finally, penetration of the throat insulation resulting from the break of the weld occurs at about $62.7 \mu \mathrm{s}(4.1 \mu \mathrm{s}$ after arrival of the shock) shutting off flux delivery to the load and both model and experiment peak at about $15 \mathrm{MA}$.

The results of this experiment indicate that the insulation system limits performance in two ways. First the, relatively conservative design of the insulator (extending well into the flux compression cavity) resulted in early stopping of armature motion, resulting in less than complete compression of flux in the generator cavity. Second, insulation in the cavity output throat was penetrated about $4 \mu \mathrm{s}$ after shock arrival by $\mathrm{HE}$ products erupting from the region of the weld joint.

Performance of the Cab-40 system could be expected to improve if (a) the machined insulator was limited to a larger radius and (b) if the time during which flux can be delivered through the output throat could be extended by strengthening the weld joint, the insulation package or both. In Figure 6 , results of an electrical test of the Cab- 40 module design with a modified insulation package are presented. For this experiment the inner radius of the machined insulator was increased to $14 \mathrm{~cm}$ to allow more complete compression of flux in the cavity. Since strengthening the weld joint required a major mechanical modification, the insulation in the output throat was strengthened by increasing its thickness from 2 to 3 $\mathrm{mm}$. Detonation time for this experiment was $39.80 \mu \mathrm{s}$. As in the previous experiment, current was measured at the input to the generator and in the $0.22 \mathrm{nH}$ load. Flux compression is seen to be more 


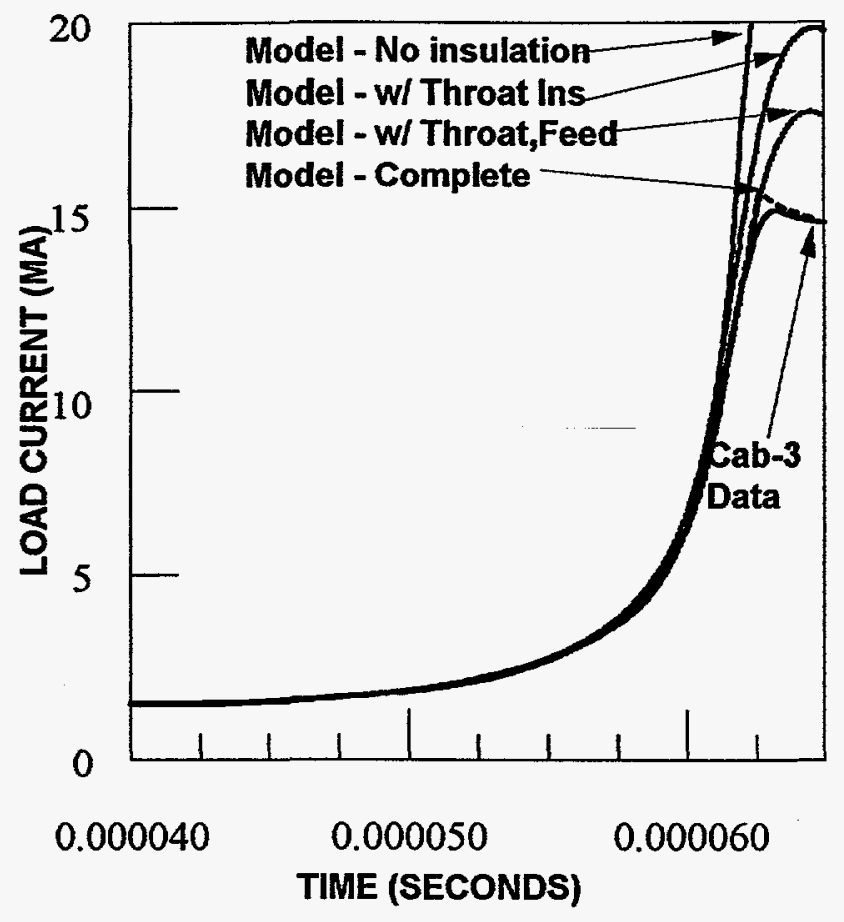

Figure 5 Performance of $C A B-3$ experiment

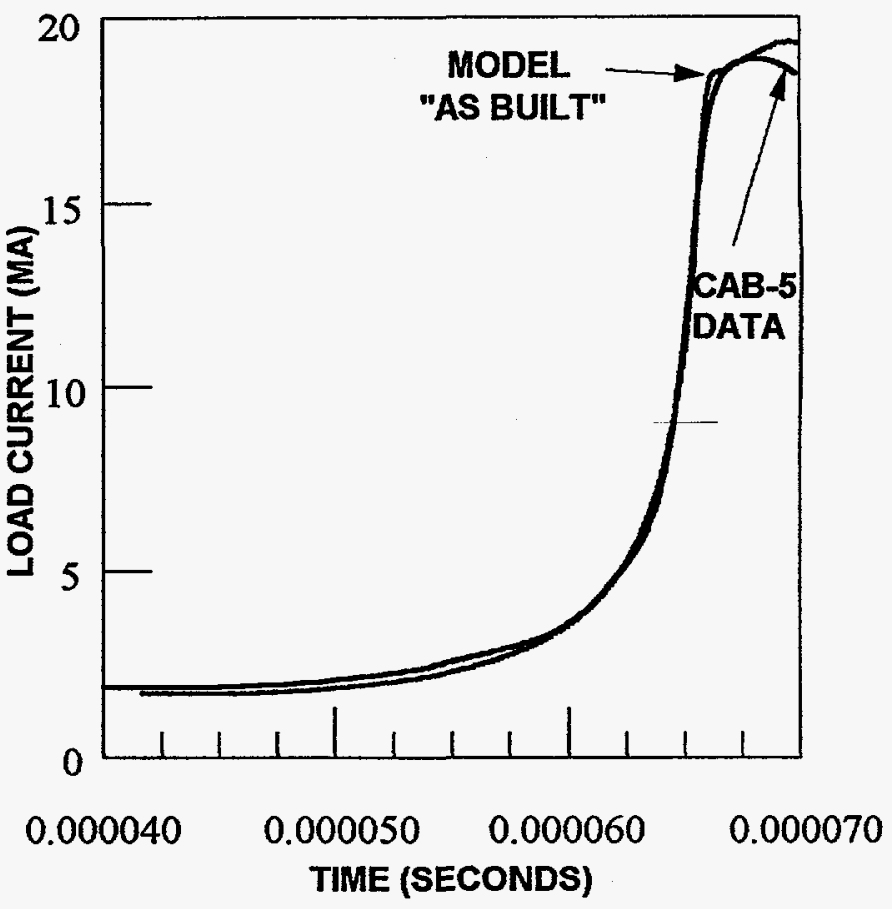

Figure 6 Performance of CAB-5 experiment

complete resulting in a peak current of about $18 \mathrm{MA}$. The model and measured currents correspond well through the time of peak current. The insulation in the throat is penetrated in the model at about $66 \mu \mathrm{s}$ (4.4 $\mathrm{\mu s}$ after detonation front arrival at 61.67.) The slightly increased time of generator operation (4.4 vs $4.1 \mu \mathrm{s}$ after shock arrival at the weld) can be attributed to increased strength of the throat insulation. However, it is evident that continuing to increase output insulation thickness will be an unsatisfactory long term solution, and improvement in weld construction will be required. In addition, most of the increased performance ( 18 vs. $15 \mathrm{MA}$ ) is attributable to the decreased quantity of insulation in the cavity.

\section{Conclusions}

The DEMG performance model has previously been applied to published data ${ }^{2}$ with reasonably good results, but lacking detailed dimension of the DEMG cavity made such comparisons inconclusive. In this paper we show good agreement between models and experimental performance for the two electrical tests done to date. The model is (surprisingly) capable of explaining fine features in the generator operation such as the impact of the moving wall on various parts of the insulation package and hence is moderately useful for improving the performance of current systems and designing future ones.

1. Chernyshev, B.E Grinevich, V.V. Vakrushev, V.I. Mamyshev, "Scaling Image of 90 Mr Explosive Magnetic Generators", in Megagauss Fields and Pulsed Power Systems (ed. VM Titov and GA Shvetsov), Nova Science, 1990, pp 347-350.

2. R.E. Reinovsky, C.A. Ekdahl, "Development of Imploding Liners with Kinetic Energies $>100 \mathrm{MJ}$ and Their Applications", in Megagauss and Megampere Pulse Technology and Applications . (ed. V.K.Chernyshev, V.D.Selemir, and L.N.Plyashkevich, VNIIEF, to be published.

3. RE Reinovsky, IR Lindemuth, SP Marsh, JH Goforth, EA Lopez, "Explosive Pulse-Power for Fusion Applications", ,/ Megagauss Magnetic Field Generation and Pulse Power Applications (ed. M Cowan and R.B. Spielman), Nova Science, 1994, pp. 671-678. 